\begin{tabular}{c} 
Jurnal LINK, 17 (1), 2021, $22-28$ \\
DOI: $10.31983 /$ link.v17i1.6509 \\
\hline$\vdots$ \\
\hline \\
http://ejournal.poltekkes-smg.ac.id/ojs/index.php/link \\
\hline
\end{tabular}

\title{
EVALUASI CONTEXT, INPUT, PROCESS, DAN PRODUCT (CIPP) DETEKSI DINI GANGGUAN JIWA DI PUSKESMAS BANYUURIP
}

\author{
Syafira Risdantia ${ }^{*}$ ); Septo Pawelas Arso ${ }^{b}$; Eka Yunila Fatmasaric \\ a, b, c Peminatan Administrasi dan Kebijakan Kesehatan, Jurusan Kesehatan Masyarakat, \\ Fakultas Kesehatan Masyarakat; Universitas Diponegoro \\ Jl. Prof. Soedarto, SH.; Tembalang ; Semarang
}

\begin{abstract}
Abstrak
Deteksi dini gangguan jiwa di Puskesmas Banyuurip sebagai tindakan pencegahan dan intervensi dini faktor risiko. Deteksi dini diharapkan mengurangi prevalensi Orang Dengan Gangguan Jiwa (ODGJ) Kabupaten Purworejo yang menempati peringkat tertinggi di Riskesdas 2018 di Jawa Tengah. Pencapaian Puskesmas Banyuurip tahun 2019 adalah 33,02\% pada usia produktif dan 80,6 \% pada usia lanjut. Capaian tersebut menunjukkan adanya aspek-aspek yang perlu diperbaiki. Tujuan dari penelitian ini adalah mengevaluasi pelaksanaan deteksi dini gangguan jiwa melalui model CIPP. Metode penelitian ini menggunakan wawancara mendalam dan observasi. Penelitian ini merupakan penelitian kualitatif pendekatan deskriptif. Aspek evaluasi meliputi context, input, process dan product. Hasil penelitian pada evaluasi aspek context bahwa kebutuhan, masalah, dan sasaran deteksi dini gangguan jiwa menjadi latar belakang perencanaan. Evaluasi aspek input menunjukkan perencanaan cukup baik walaupun terdapat keterbatasan tenaga, dana, dan infrastruktur. Evaluasi aspek process bahwa pelaksanaan edukasi, rujukan, dan pelaporan kurang optimal dilaksanakan. Evaluasi aspek product dalam kriteria cukup baik dengan beberapa aspek perlu ditingkatkan. Antar aspek memiliki keterkaitan sehingga perbaikan satu aspek harus diikuti oleh aspek lainnya.
\end{abstract}

Kata kunci: deteksi dini; evaluasi; gangguan jiwa

\begin{abstract}
[CONTEXT INPUT PROCESS PRODUCT (CIPP) EVALUATION OF EARLY DETECTION OF MENTAL DISORDERS IN PUSKESMAS BANYUURIP, PURWOREJO REGENCY] Early detection of mental disorders in Puskesmas Banyuurip as early intervention of risk factors. It is also expected to reduce the prevalence of Orang Dengan Gangguan Jiwa (ODGJ) Purworejo Regency which ranks highest at the Riskesdas 2018 in Central Java. Puskesmas Banyuurip achievements in 2019 were $33.02 \%$ at productive age and $80.6 \%$ at elderly. These achievements show that aspects need to be improved. The purpose of this study is to evaluate the implementation of early detection of mental disorders through the CIPP model. This research method uses in-depth interviews and observations. This research is qualitative research descriptive approach. Evaluation aspects include context, input, process and product. The results on the context aspects of needs, problems, and goals are the background. The input aspect shows that is quite good even though there are limited staff, funds, and infrastructure. Process aspects indicate the implementation of education, referral, and reporting is not optimal. Product aspects are quite good with improvement. Between aspects have a linkage, so the improvement of one must be followed by other aspects.
\end{abstract}

Keywords: early detection; evaluation; mental disorders

\section{Pendahuluan}

Gangguan jiwa, neurologis, dan penggunaan narkoba menyumbang $13 \%$ dari total beban

*) Correspondence (Syafira Risdanti)

E-mail: syafirarisdanti@gmail.com global pada tahun 2004. Data world health organization (WHO) bahwa kondisi depresi menyumbang $4,3 \%$ dari beban global penyakit dan termasuk yang terbesar penyebab kecacatan di seluruh dunia terutama bagi perempuan. Konsekuensi dari segi ekonomi memperkirakan 
bahwa dampak global dari gangguan jiwa dalam hal output ekonomi yang hilang akan berjumlah US \$ 16,3 juta antara tahun 2011 dan 2030.(WHO, 2013)

Kabupaten Purworejo menjadi kabupaten dengan prevalensi prevalensi Orang Dengan Gangguan Jiwa (ODGJ) tertinggi se-Jawa Tengah sebesar 2,262\% atau 12.535 jiwa. Deteksi dini sebagai upaya dalam menemukan kasus gangguan jiwa. Setelah kasus ditemukan upaya rujukan untuk pengobatan segera semakin meningkat sehingga menurunkan prevalensi kasus.(Kementerian Kesehatan, 2019)

Deteksi dini gangguan jiwa di Puskesmas Banyuurip mulai digalahkan tahun 2019 karena adanya arahan dari Dinas Kesehatan Kabupaten Purworejo. Dengan target 100\%, capaian deteksi dini gangguan jiwa sampai 2019 pada usia produktif berada di angka 33,02\% (3.265 jiwa dari 4.051 jiwa) dan pada usia lanjut di angka 80,6\% (5.611 jiwa dari 16.992 jiwa). Sedangkan temuan kasus kejiwaan dari deteksi dini tahun 2019 tidak ditemukan.

Berdasarkan studi pendahuluan, penemuan ODGJ sebanyak 83 orang di Puskesmas Banyuurip merupakan laporan dari perangkat desa dengan temuan penderita gangguan jiwa berat. Data yang terlapor di Dinkes tersebut kemudian dibandingkan dengan informasi Puskesmas belum menggambarkan keadaan yang sebenarnya di lapangan. Sehingga deteksi dini perlu dievaluasi untuk membuktikan sejauh mana kredibilitas pelaksanaannya. Penelitian sebelumnya oleh Masta Hosthasian dkk di Puskesmas Bandarharjo Semarang, pelaksanaan deteksi dini gangguan jiwa masih menemui hambatan yakni Puskesmas yang belum bersikap proaktif, SOP belum tersedia, dan perencanaan program dilaksanakan bersamaan dengan evaluasi kinerja program. Akibatnya dalam melakukan pelayanan standar bagi ODGJ berat baru mencapai 94,7\% dari target 100\%.(Masta Hothasian, Suryawati dan Fatmasari, 2019)

Evaluasi model CIPP (Context Input Process Product) banyak digunakan untuk melakukan evaluasi dalam penyediaan layanan publik bidang kesehatan dengan kerangka kerja yang komprehensif. Belum dilakukan evaluasi terhadap kendala pelaksanaan kegiatan dan kesesuaian kegiatan yang telah dilaksanakan terhadap permasalahan yang ada. Evaluasi kemudian berguna dalam memperbaiki dan mengembangkan program.(WHO, 2007)

\section{Metode}

Penelitian ini merupakan penelitian kualitatif pendekatan deskriptif. Subjek penelitian dipilih dengan teknik purposive sampling atau dengan kriteria semua pihak yang terlibat dalam pelaksanaan deteksi dini gangguan jiwa. Penelitian mulai dari bulan Februari sampai Mei 2020 di Puskesmas Banyuurip, Kabupaten Purworejo.

Pengumpulan data didapatkan dari wawancara mendalam kepada informan dan observasi di lapangan. Informan terdiri dari informan utama dan triagulasi. Informan utama yaitu Kepala Puskesmas, Koordinator Skrining Usia Produktif, Koordinator Skrining Usia Lanjut, dan Kader. Informan triangulasi terdiri dari Penanggung Jawab Program Kesehatan Jiwa Dinas Kesehatan Kabupaten Purworejo, masyarakat usia produktif dan masyarakat usia lanjut. Sedangkan sumber data lainnya didapatkan dengan telaah pustaka dan dokumentasi.

Objek dalam penelitian ini menggunakan kerangka evaluasi CIPP Stufflebem yaitu evaluasi context, input, process, dan product. Aspek context meliputi masalah, kebutuhan, sasaran, dan tujuan. Aspek input meliputi pedoman, jadwal, tenaga, dana, dan sarana prasarana. Aspek process meliputi deteksi dini, edukasi, rujukan, dan pencatatan pelaporan. Sedangkan aspek product yaitu capaian deteksi dini. Masing-masing aspek diuraikan dalam instrumen pedoman wawancara dan observasi, serta saling berhubungan. Penelitian yang dilakukan juga telah lolos kaji etik dari Fakultas kesehatan Masyarakat Universitas Diponegoro Nomor: 5/EA/KEPK-FKM/ 2020.

\section{Hasil dan Pembahasan}

Deteksi dini gangguan jiwa merupakan upaya pencegahan dan penanganan awal gangguan kejiwaaan. Pelaksanaannya dilakukan melalui Posbindu PTM dan Posyandu Lansia dengan kader sebagai pelaksana lapangan. Puskesmas Banyuurip memiliki inovasi dalam pelayanan kejiwaan seperti Gerdu Panjimas (Gerakan Terpadu Pelayanan Jiwa Masyarakat) dan menjadi perwakilan pelatihan di tingkat provinsi.

\section{Evaluasi Aspek Context}

Evaluasi pada aspek context deteksi dini gangguan jiwa membantu identifikasi masalah, kebutuhan, dan sasaran untuk mencapai tujuan. 
a. Masalah

Prevalensi ODGJ di Kabupaten Purworejo sebesar 2,262\% pada 2018. Hal ini dierkuat dengan adanya masalah gangguan jiwa di wilayah kerja Puskesmas Banyuurip, informan menjelaskan bahwa terdapat beberapa masalah gangguan jiwa di wilayah kerja Puskesmas Banyuurip. Masalah kejiwaan disebabkan dari masalah ekonomi maupun faktor lainnya.

"Ya ada hubungannya ya dengan kasus jiwa dan prevalensi tertinggi. Karena lansia itu lebih rentan misalnya pikun." (IU 3)

Masalah gangguan jiwa dibuktikan dengan data penemuan ODGJ pada tahun 2019 sebanyak 83 orang yang dilaporkan ke Dinkes Kabupaten Purworejo. Sebagian besar penderita merupakan usia produktif sedangkan lansia juga rentan depresi. Menurut WHO dalam Idaiani, penyakit kejiwaan banyak menimbulkan beban kesehatan masyarakat. (Idaiani, 2016) Dalam penelitian Suci Pujiati diperlukan sumber data dan informasi dalam penetapan prioritas berdasarkan pengetahuan masing-masing kelompok, saran dan pendapat narasumber. (Pujiati, 2018)

b. Kebutuhan

Besarnya masalah yang terjadi di lapangan tidak sejalan dengan kebutuhan kesehatan jiwa yang berkembang pada masyarakatnya. Begitu pula dengan informan triangulasi yang menyatakan dengan adanya deteksi dini di Posbindu PTM dan Posyandu Lansia tidak menjadikan anggapan kesehatan jiwa masyarakat menjadi penting. Kebanyakan masyarakat merasa tidak butuh melakukan deteksi dini karena merasa sehat.

"Sebenernya butuh tapi masyarakatnya yang kadang males. Karena dia merasa sehat jadi ga usah kontrol." (IU 4)

Kebutuhan akan timbul apabila individu memerlukan pelayanan kesehatan. Cullis dan West dalam Santoso dalam Kusumawati menyatakan bahwa kebutuhan yang dirasakan terhadap pelayanan kesehatan merupakan penjumlahan dari kebutuhan fisiologis dan psikologis individu terhadap suatu pelayanan kesehatan. Kondisi psikologis mempengaruhi kebutuhan masyarakat terhadap pelayanan kesehatan. Dengan edukasi dapat meningkatkan kepedulian individu terhadap kesehatan jiwanya.(Kusumawati, 2016)

c. Sasaran

Jenis dan jumlah sasaran deteksi dini gangguan jiwa ditentukan oleh Dinkes Kabupaten yang bekerjasama dengan Disdukcapil maupun BPS Kabupaten. Namun pada akhir tahun, laporan tetap harus mencantumkan jumlah sasaran real. Sasaran deteksi dini gangguan jiwa pada usia produktif berjumlah 16.992 jiwa dan usia lanjut berjumlah 4051 jiwa.

"Untuk sasaran kita jumlahnya dari Disdukcapil atau BPS, dianggap dari sasaran. Tapi di akhir tahun dari Dinas mengharapkan angka real dari PIS PK." (IU 1)

Masalah kesehatan jiwa di wilayah kerja Puskesmas Banyuurip juga dibuktikan dengan adanya data ODGJ yang penderitanya kebanyakan dalam usia produktif. Selaras dengan penelitian Mubasyiroh, Putri, dan Tjandrarini menunjukkan bahwa faktor usia 16 tahun ke atas mempunyai risiko $>2$ kali mengalami gejala mental emosional. Bahwa semakin tinggi usia maka semakin besar risiko mengalami gejala mental emosional. Pada usia lanjut lebih sering mengalami kepikunan sehingga cenderung tidak mandiri. (Mubasyiroh et al., 2017) Penelitian Sutikno dalam kelompok lansia di Kota Kediri menunjukkan bahwa prevalensi gangguan kesehatan mental dalam penelitian ini cukup tinggi, yaitu 25\%. Semakin tua usia lansia, maka semakin kurang dalam kemandirian. Ketidakmandirian tersebut menyebabkan lansia mudah mengalami depresi.'(Sutikno, 2015)

d. Tujuan

Dari masalah, kebutuhan, dan sasaran maka ditentukan tujuan. Tujuan yang ingin dicapai yaitu semua sasaran mendapatkan pelayanan deteksi dini, upaya promotif preventif kesehatan jiwa, dan faktor risiko dapat ditangani lebih awal. Tujuan tersebut sesuai Peraturan Pemerintah Nomor 2 Tahun 2018 tentang Standar Pelayanan Minimal. Sedangkan tujuan jangka panjangnya adalah menurunkan prevalensi kasus sesuai tujuan SPM Kesehatan.

"Untuk deteksi secara dini lebih awal, intervensi faktor risiko, dan tata laksana secara awal. Deteksi ini juga bisa menurunkan prevalensi dari ODGJ." (IU 1)

Idaiani menyatakan bahwa integrasi kesehatan jiwa pada pelayanan primer diartikan sebagai adanya pelayanan kesehatan jiwa di tingkat primer atau Puskesmas. Dengan adanya deteksi dini gangguan jiwa diharapkan puskesmas dapat menuntaskan penyakit bidang psikiatri secara komprehensif. 
(Idaiani, 2016) Suhbah, Suryawati, dan Kusumawati menerangkan bahwa tujuan dari penyelenggaraan Posbindu PTM adalah untuk meningkatkan peran serta masyarakat dalam melakukan pencegahan dan deteksi dini faktor risiko PTM. (Suhbah, Suryawati dan Kusumastuti, 2019)

\section{Evaluasi Aspek Input}

Evaluasi pada aspek input menguraikan perencanaan sumber daya dalam rangka persiapan pelaksanaan deteksi dini gangguan jiwa. Sumber daya meliputi pedoman, jadwal, tenaga, dana, dan sarana prasarana.

a. Pedoman

Pedoman deteksi dini gangguan jiwa yaitu Permenkes Nomor 4 Tahun 2019. Sedangkan KAK Program Skrining Kesehatan Puskesmas Banyuurip sebagai pedoman teknis pelaksanaan. KAK memuat keterangan latar belakang, tujuan, tata cara pelaksanaan, hingga monitoring dan evaluasi kegiatan.

"Tidak ada. Adanya copyan materi waktu pelatihan itu saya minta tapi belum sempat tak baca." (IU 5)

KAK disusun oleh Puskesmas dan disebarluaskan ke bidan dan perawat, sedangkan kader tidak diberikan. Penelitian di Puskesmas Sukolilo I bahwa sudah tersedia pedoman Posbindu PTM bagi Kader. Namun, buku Panduan ini belum menjangkau ke semua kader.(Suhbah, Suryawati dan Kusumastuti, 2019)

b. Jadwal

Rentang waktu pelaksanaan deteksi dini mulai Februari sampai November pada 2019 dan Februari sampai Desember pada 2020. Dalam 1 tahun, semua sasaran harus mendapatkan pelayanan deteksi dini ini.

"Kita sudah punya jadwal, oleh Pukesmas lalu koordinasikan minimal ke kader atau pemerintah desa. Jadwal itu bisa berubah-ubah, mundur, bisa menyesuaikan masing masing desa, misal saat itu ada pilkada." (IU 1)

Dalam penyusunan jadwal, Puskesmas melibatkan Bidan dan Perawat serta persetujuan desa setempat. Dengan banyaknya sasaran yang tidak hadir, kader melakukan metode sweeping dengan jadwal yang berbeda. Selaras dengan Sicilia, Dewi, dan Padmawati (2018) bahwa jadwal rutin atas kesepakatan masyarakat yang diwakili oleh kader dengan petugas kesehatan dan atau Bidan desa. Kesepakatan diambil berdasarkan kondisi masing-masing masyarakat di kelurahan terkait. (Sicilia, Dewi dan Padmawati, 2018) c. Tenaga

Semua unsur terlibat dalam sumber daya tenaga yaitu koordinator, bidan, perawat, dan kader. Meskipun masih dalam keterbatasan jumlah pada perawat pembina. Jumlah bidan sebanyak 13 dan perawat sebanyak 5 untuk membina 14 desa. Pelayanan luar gedung dapat dimanfaatkan untuk mengatasi keterbatasan tersebut. Sedangkan kader terbatas pada keterampilannya.

"Ada saya dan yang lansia. Setiap Posbindu pasti ada petugas Puskesmas. Kayak tadi ada Bu Bidan. Ada kader Posbindu juga." (IU 2)

Pelatihan sudah dilaksanakan bagi pelaksana yaitu bidan, perawat, dan kader. Pelatihan berupa penggunaan instrumen. Perlu adanya pelatihan di tiap-tiap pos agar semua kader dapat melakukan deteksi dini. Seperti disebutkan dalam penelitian Saputra dkk bahwa berdasarkan kuantitasnya, jumlah SDM yang dibutuhkan untuk memaksimalkan pelaksanaan SPM dibutuhkan 4-6 orang kader, dan kader tersebut sebaiknya berasal dari masyarakat daerah itu sendiri, dan secara kualitas keberhasilan pelaksanaan posbindu didukung oleh kader yang telah mendapat pelatihan. (Himawan Saputra et al., 2017)

d. Dana

Dalam pendanaan 2019, Dinas Kesehatan dalam APBD dialokasikan untuk pelatihan pemahaman instrumen bagi kader. Sedangkan Puskesmas dalam BOK menyiapkan dana untuk perbanyak formulir skrining.

"Dana hanya untuk pelatihan kader, itu dari dana Dinas, dibebankan kepada APDB Dinkes. Formulir diperbanyak Puskesmas." (IT 1)

Alokasi dana masih belum memenuhi harapan. Seperti dana untuk transport kader maupun pengadaan media KIE. Primiyani, Masrul, dan Hardisman menyatakan bahwa pembiayaan Posbindu didapatkan dari berbagai macam sumber. Anggaran biaya untuk program PTM termasuk didalamnya Posbindu PTM baik yang didanai dengan APBD maupun BOK Puskesmas.(Primiyani, Masrul dan Hardisman, 2019)

e. Sarana Prasarana

Sarana deteksi dini gangguan jiwa berupa formulir SRQ dan GDS, formulir rujukan, formulir rekapitulasi, buku PPDGJ III, dan media KIE sudah tersedia. Sarana ini khususnya pada formulir dicetak saat dibutuhkan. Namun karena keterbatasan dana sarana berupa media KIE khusus kesehatan jiwa terbatas.

"Itu SRQ dan yang untuk lansia contohnya dari 
Dinkes. Tapi kita perbanyak sendiri sesuai jumlahnya. Formulir pelaporannya ga ada, pelaporan setelah pelaksanaan langsung dikumpulkan." (IU 2)

Penelitian Roesli dan Bachtiar (2018) menyebutkan bahwa media komunikasi informasi dan edukasi (KIE) terkait keswa yang dimiliki oleh Puskesmas sangat sedikit. Media konseling yang ada berupa lembar balik kesehatan jiwa dan tidak semua Puskesmas memiliki. Selain itu sarana seperti KAK skrining, formulir skrining, dan formulir rujukan terbatas pada petugas kesehatan seperti bidan dan perawat, belum dibagikan ke kader.(Roeslie dan Bachtiar, 2018)

\section{Evaluasi Aspek Process}

Dalam proses pelaksanaan deteksi dini gangguan jiwa terdiri dari deteksi dini, edukasi, rujukan kasus, dan pencatatan pelaporan.

a. Deteksi Dini

Deteksi dini gangguan jiwa dilaksanakan di Posbindu PTM dan Posyandu Lansia. Selain itu juga terdapat metode sweeping untuk mendatangi sasaran yang tidak hadir. Sweeping hanya dilaksanakan di beberapa desa, hal ini karena keterbatasan tenaga kader dan dana.

Deteksi dengan metode wawancara menggunakan pertanyaan pada instrumen SRQ dan GDS. Masih ada beberapa hal yang tidak sesuai dengan pedoman deteksi dini seperti metode penyampaian dan validitas jawaban. Beberapa pertanyaan hanya ditanyakan dengan satu pertanyaan dan tidak disertai sebab gangguan yang muncul. Pendampingan petugas sangat diperlukan sehingga deteksi dapat optimal.

"Sakjane kalo SRQ itu dari rumah ke rumah, individu ya mbak, nanti ditemukan apa. Itu sebenernya maunya program ya seperti itu. Tapi kita terbatasnya di SDM, kader, kader gaada insentif. Aslinya mendata per RT dikategori sehat, ODMK atau ODGJ. Tapi pelaksanaannya digabung Posbindu." (IU 2)

Deteksi dilakukan oleh petugas yang telah terlatih. Sejalan dengan penelitian Hothasian, Suryawati, dan Fatmasari (2019) menyatakan deteksi dini dilakukan sebagai kegiatan menggolongkan pasien dengan gangguan jiwa berdasarkan keluhan psikis yang frekuensinya berkelanjutan (pusing, sakit perut, tidak bisa tidur) walaupun pada saat dilakukan pemeriksaan fisik pasien dinyatakan sehat. Penggolongan (deteksi dini) juga bisa didapatkan berdasarkan hasil pertanyaan yang dilakukan oleh petugas kesehatan. (Masta Hothasian, Suryawati dan Fatmasari, 2019)

b. Edukasi

Hasil deteksi dini kemudian ditindak lanjut dengan edukasi atau rujukan. Apabila faktor risiko dibawah 6 dilakukan edukasi. Edukasi biasa dilakukan dengan model ceramah maupun personal. Edukasi ceramah bisa juga dilakukan di arisan maupun PKK. Sedangkan edukasi setelah hasil deteksi disebut konseling

"Kan dari pemeriksaan ada penyimpangan, tapi kalau GDS itu jarang. Kita lakukan edukasi, Bidan Desa yang melakukan. Oh itu kader belum bisa. (IU 3)

Edukasi belum dilaksanakan dengan baik karena kurangnya keterampilan kader. Edukasi juga kurang optimal karena adanya keterbatasan media penyuluhan pada aspek input. Sejalan dengan penelitian Uzhma dkk (2019) bahwa penyuluhan kesehatan dilaksanakan melalui kunjungan rumah, instrumen yang digunakan berupa pinkesga dan materi penyuluhan.(Uzhma et al., 2019)

c. Rujukan Kasus

Hasil deteksi dini dengan skor di atas 6 diberikan edukasi dan formulir rujukan untuk pemeriksaan lebih lanjut di Poli Jiwa Puskesmas. Rujukan dapat dilakukan oleh petugas terlatih, sehingga banyak kader yang belum mampu melaksanakan. Rujukan diberikan sesuai faktor risiko yang dialami pasien.

"Kalau rujukan pasti ada petugas. Dari petugas Puskesmas. Ada formulirnya. Itupun kadang yang sudah dirujuk ga dateng, mbak. Karena mungkin takut yang pertama. Apalagi yang umum kan pasti takut bayar." (IU 2)

Lain halnya dengan penelitian Isnawati, Lestari, dan Hapsari (2018) yang menyebutkan bahwa peran kader kesehatan jiwa dalam rujukan umumnya mendata pasien yang mengalami gangguan jiwa, kemudian kader lapor ke Puskesmas. Bagi peserta yang masuk pada kriteria buruk pada hasil pemeriksaan harus didiagnosis oleh Puskesmas. Dengan membawa surat rujukan sesuai dengan kriteria agar peserta mendapat penanganan yang baik sesuai kebutuhannya. (Iswanti, Lestari dan Hapsari, 2018)

d. Pencatatan Pelaporan

Pencatatan dilakukan pada jumlah kunjungan dan skrining. Sedangkan pencatatan faktor risiko belum dilakukan dengan baik. Pelaporan dilakukan sebulan 
sekali oleh kader ke Koordinator Skrining, sedangkan tiga bulan sekali oleh Koordinator ke Dinkes. Pelaporan dari klinik pratama belum terintegrasi.

"Dilaporkan tercover di laporan Posbindu dan Posyandu Lansia itu selama 1 tahun. Tapi sayangnya yang skrining tidak ada laporan khususnya." (IT 1)

Pelaporan dilakukan secara offline oleh kader hal ini karena pelaporan online dilakukan oleh Koordinator Skrining Puskesmas meskipun sudah terdapat kader terlatih untuk itu. Seperti dalam penelitian Rokib dan Junadi (2019) bahwa proses pencatatan dan pelaporan berbasis web masih tidak memadai meskipun staf telah menerima pelatihan. Pelaporan hasil deteksi dini dari kader merupakan sumber data yang penting untuk dilaporkan secara rutin. (Rokib dan Junadi, 2019) Juga dalam penelitian Sutini dan Hidayati, kader kesehatan jiwa selalu melaporkan hasil deteksinya kepada pihak puskesmas untuk di follow up dan harus terus dipantau. (Sutini dan Hidayati, 2017)

\section{Evaluasi Aspek Product}

Produk deteksi dini berupa capaian. Secara umum capaian $100 \%$ tetap menjadi target. Capaian mengenai proporsi faktor risiko belum ada. Capaian ini tentunya karena perbedaan jadwal pelaksanaan, keterbatasan tenaga, dan metode pelaksanaan deteksi dini. Dinas Kesehatan menilai bahwa capaian deteksi dini gangguan jiwa Puskesmas Banyuurip dalam kriteria cukup bagus dengan tetap pada target 100\%. Koordinasi antar pihak diperlukan karena menurut Dinas Kesehatan angka capaian ini menjadi tanggung jawab Puskesmas.

"Ya harusnya 100\% itu harga mati. Tapi dalam pelaksanaan masih ada hambatan yang memang perlu dicari Puskesmas juga agar bisa mencapai itu." (IT 1)

Dalam penelitian Suhbah, Suryawati, dan Kusumawati (2019) bahwa belum ada penetapan target cakupan kegiatan dan proporsi faktor risiko PTM yang dapat digunakan untuk mengukur keberhasilan program Posbindu PTM. Data kegiatan hanya terkait jumlah kunjungan tiap bulannya. (Primiyani, Masrul dan Hardisman, 2019) Sedangkan dalam penelitian Posbindu di Kota Solok menyatakan bahwa dalam hasil pelaksanaan posbindu PTM belum tercapai sesuai target. Cakupan kunjungan tersebut karena masih adanya keterbatasan dalam sarana dan prasarana serta kurangnya sosialisasi baik itu lintas program. (Primiyani, Masrul dan Hardisman, 2019)

\section{Simpulan dan Saran}

Deteksi dini gangguan jiwa di Puskesmas Banyuurip merupakan upaya penemuan kasus jiwa. Pada evaluasi konteks diperlukan adanya pengembangan pada aspek kebutuhan masyarakat. Evaluasi pada input, sumber daya disediakan namun masih terbatas pada tenaga dan sarana prasarana. Pemanfaatan sumber daya lain seperti kader dan waktu kerja di luar gedung. Evaluasi pada proses, pelaksanaan sesuai pedoman meskipun deteksi dini, edukasi, dan rujukan belum optimal dilaksanakan oleh kader. Sedangkan evaluasi produk berupa capaian deteksi dini gangguan jiwa pada tahun 2019, perlu adanya laporan faktor risiko dari hasil deteksi dini.

Bagi Puskesmas sebaiknya mengadakan edukasi menyeluruh dan peningkatan keterampilan kader. Selain itu jadwal pelaksanaan di sore hari berpeluang menjaring sasaran usia produktif lebih banyak. Dinas Kesehatan perlu meningkatkan koordinasi dengan sektor lain, seperti pada pendataan sasaran real dengan Dinas Kependudukan dan Catatan Sipil maupun promotif preventif kesehatan Jiwa dengan Dinas Sosial.

\section{Ucapan Terima Kasih}

Terima kasih peneliti ucapkan kepada Puskesmas Banyuurip, Dinas Kesehatan Kabupaten Purworejo, dan Fakultas Kesehatan Masyarakat Universitas Diponegoro yang telah memberikan dukungannya selama proses penelitian ini. Terima kasih banyak kami ucapkan pada semua pihak yang telah membantu kegiatan penelitian ini. ....

\section{Daftar Pustaka}

Himawan Saputra, M. et al. (2017) "Analisis Sistem Infromasi Faktor Resiko Hipertensi Berbasis Posbindu di Dinas Kesehatan Kabupaten Sidoarjo," in Prosiding Seminar Nasional Hasil Penelitian dan Pengabdian Masyarakat Seri Ke-1 Tahun, hal. 7-17.

Idaiani, S. (2016) "Penyakit-Penyakit di Bidang Psikiatri yang Harus Dituntaskan di Puskesmas," Jurnal Kebijakan Kesehatan Indonesia: JKKI, 5(4), hal. 168-175. doi: 10.22146/JKKI.V5I4.30532.

Iswanti, D. I., Lestari, S. P. dan Hapsari, R. D. (2018) "Peran Kader Kesehatan Jiwa dalam Melakukan Penanganan Gangguan Jiwa," Jurnal Ilmu Keperawatan 
Jiwa, 1(1), hal. 33-37.

Kementerian Kesehatan (2019) Laporan Riskesdas 2018. Jakarta.

Kusumawati, R. M. (2016) “Analisis Kebutuhan (Need) Masyarakat terhadap Pelayanan Kesehatan di Puskesmas Mulyorejo Kota Surabaya," Jurnal Penelitian Kesehatan Suara Forikes, 7(4), hal. 180-182. doi: 10.33846/SF.V7I4.46.

Masta Hothasian, J., Suryawati, C. dan Fatmasari, E. Y. (2019) "Evaluasi Pelaksanaan Program Upaya Kesehatan Jiwa di Puskesmas Bandarharjo Kota Semarang tahun 2018," Jurnal Kesehatan Masyarakat (e-Journal), 7(1), hal. 2356-3346. Tersedia pada:

http://ejournal3.undip.ac.id/index.php /jkm (Diakses: 14 November 2019).

Mubasyiroh, R. et al. (2017) "Determinan Gejala Mental Emosional Pelajar SMP-SMA di Indonesia Tahun 2015," Buletin Penelitian Kesehatan, 45(2), hal. 103-112. doi: 10.22435/bpk.v45i2.5820.103-112.

Primiyani, Y., Masrul, M. dan Hardisman (2019) "Analisis Pelaksanaan Program Pos Pembinaan Terpadu Penyakit Tidak Menular di Kota Solok," Jurnal Kesehatan Andalas, 8(2), hal. 399-406. doi: 10.25077/jka.v8.i2.p399-406.2019.

Pujiati, S. (2018) "Pemetaan Masalah dan Penentuan Prioritas Program Kesehatan pada Masyarakat Kelurahan Gerem, Kecamatan Grogol, Kota Cilegon," HEARTY Jurnal Kesehatan Masyarakat, 6(2), hal. 1-9. doi: 10.32832/hearty.v6i2.1278.

Roeslie, E. dan Bachtiar, A. (2018) "Analisis Persiapan Implementasi Program Indonesia Sehat dengan Pendekatan Keluarga (Indikator 8: Kesehatan Jiwa) di Kota Depok tahun 2018 | Roeslie | Jurnal Kebijakan Kesehatan Indonesia: JKKI," Jurnal Kebijakan Kesehatan Indonesia, 7(2), hal. 64-73. Tersedia pada: https://jurnal.ugm.ac.id/jkki/article/vi ew/36222/22506 (Diakses: 10 Mei 2020).

Rokib, Z. M. dan Junadi, P. (2019) “An Analysis on The Preparedness for Implementing The Minimal Standards for Service in The
Health Field at Depok City in 2017," Journal of Indonesian Health Policy and Administration, 4(1), hal. 16-21.

Sicilia, G., Dewi, F. S. T. dan Padmawati, R. S. (2018) “Evaluasi Kualitatif Program Penyakit Tidak Menular berbasis Posbindu di Wilayah Kerja Puskesmas Muara Bungo I," Jurnal Kebijakan Kesehatan Indonesia, 7(2), hal. 88-92. doi: 10.22146/JKKI.36117.

Suhbah, W. D. A., Suryawati, C. dan Kusumastuti, W. (2019) "Evaluasi Pelaksanaan Program Pos Pembinaan Terpadu Penyakit Tidak Menular (Posbindu PTM) Puskesmas Sukolilo I Kabupaten Pati," Jurnal Kesehatan Masyarakat (e-Journal), 7(4), hal. 647-657.

Sutikno (2015) “Faktor-Faktor yang Berhubungan dengan Gangguan Kesehatan Mental pada Lansia: Studi Cross-Sectional pada Kelompok Jantung Sehat Surya Group Kediri," Jurnal Wiyata: Penelitian Sains dan Kesehatan, 2(1), hal. 1-8. Tersedia pada: https://ojs.iik.ac.id/index.php/wiyata/ article/view/26/26 (Diakses: 20 Mei 2020).

Sutini, T. dan Hidayati, N. O. (2017) “Gambaran Deteksi Dini Kesehatan Jiwa di Desa Ranjeng dan Cilopang Kabupaten Sumedang," Jurnal Keperawatan BSI, 5(1), hal. 24-28. doi: 10.31311/.V5I1.1772.

Uzhma, L. S. et al. (2019) "Analisis Pelaksanaan Program Indonesia Sehat dengan Pendekatan Keluarga Bagi Orang dengan Gangguan Jiwa Berat di Puskesmas (Studi Kasus Skizofrenia di Puskesmas Kedungmundu Kota Semarang)," Jurnal Kesehatan Masyarakat (e-Journal), 7(2), hal. 1-9. doi: $10.14710 / \mathrm{mkmi} .18 .2 .23-27$.

WHO (2007) "How to Evaluate The Programme," in Drinking and Driving: a road safety manual for decision-makers and practitioners. Switzerland, hal. 121-136.

WHO (2013) "Mental Health Action Plan 20132020," WHO Library Cataloguing-inPublication Data, hal. 1-50. doi: ISBN 978 9241506021. 